\title{
Desempenho e Digestibilidade in vivo de Cordeiros Alimentados com Dietas Contendo Canola em Grão Integral em Diferentes Formas ${ }^{1}$
}

\section{Vanderlei Bett ${ }^{2}$, Geraldo Tadeu dos Santos ${ }^{3 *}$, Luiz Januário Magalhães Aroeira ${ }^{4}$, Hèléne V. Petit $^{5}$, Priscila Gongora Dias ${ }^{6}$, Thelma Cristina dos Santos Soares Leggi ${ }^{7}$, Karla de Faria Peron ${ }^{8}$, Lúcia Maria Zeoula ${ }^{3 *}$}

RESUMO - O desempenho e a digestibilidade dos nutrientes de cordeiros alimentados com concentrados formulados com farelo de soja (FS), canola integral (CI) canola quebrada (CQ) ou canola peletizada (CP) e feno de aveia, fornecidos na relação $30 / 70$ (volumoso/ conconcentrado, \%MS) foram avaliados. Vinte oito cordeiros machos com idade inicial entre 60 e 90 dias e $17 \mathrm{~kg}$ PV foram distribuídos em delineamento inteiramente casualizado. As ingestões (g/d) de MS, PB, FDA, FDN e EB (Mcal/dia), o ganho médio diário e a conversão alimentar, foram semelhantes. Não houve diferenças para digestibilidade aparente da MS, PB e EB, exceto para digestibilidade de FDN $(46,84 ; 60,11 ; 50,10$; e 38,88\%) e FDA $(45,84 ; 54,19 ; 46,57$; e 29,59\%) para FS, CI, CQ e CP, respectivamente. Houve menor retenção de nitrogênio para $\mathrm{CP}(3,0 \mathrm{~g} / \mathrm{d})$ em comparação às outras dietas (entre 5,0 e 7,3 g/d). Os tratamentos não diferiram na concentração de propionato, mas reduziram as concentrações de butirato $(7,08 ; 4,87 ; 4,08 ;$ e 4,29 $\mu \mathrm{M} / \mathrm{mL}$ de líquido ruminal) e N-amoniacal (12,17; 8,69; 8,40; e 7,66 mg/100 mL de líquido de rúmen). O uso de canola, nas diferentes formas, não influenciou a ingestão e a digestão, proporcionando desempenho semelhante entre os tratamentos.

Palavras-chave: AGV, canola, cordeiro, digestibilidade, n-amoniacal, $\mathrm{pH}$ ruminal

\section{Performance and Digestibility in vivo of Lambs Fed Diets with Whole Canola Grain in Different Forms}

\begin{abstract}
The performance and digestibility of nutrients of lambs fed concentrates formulated with soybean meal (SM) and whole canola grain (WC), cracked canola grain (CC) or pelleted canola (PC) and oat hay, fed in a 30:70 (forage to concentrate ratio, \%DM) were evaluated. Twenty-eight male lambs with initial age from 60 to 90 days and $17 \mathrm{~kg} \mathrm{LW}$ were allotted to a completely randomized design. The intakes (g/d) of DM, CP, ADF, NDF and GE (Mcal/d), the average daily gain and feed: gain ratio, were similar. There were no differences for apparent digestibilities of MS, PB and GE, except for the NDF digestibility (46.84, 60.11, 50.10, and 38.88\%) and ADF (45.84, 54.19, 46.57 , and $29.59 \%$ ) for SM, WC, CC and PC, respectively. There was lower nitrogen retention for CP (3.0 g/d) comparing to the other diets (between 5.0 and $7.3 \mathrm{~g} / \mathrm{d}$ ). The treatments did not differ on the propionate concentration, but reduced the concentrations of butyrate ( 7.08 , $4.87,4.08$, and $4.29 \mu \mathrm{M} / \mathrm{mL}$ of ruminal fluid) and ammonia-N $(12.17,8.69,8.40$, and $7.66 \mathrm{mg} / 100 \mathrm{~mL}$ of ruminal fluid). The use of canola, in the different forms, did not affect the intake and digestion, providing similar performance among the treatments.
\end{abstract}

Key Words: VFA, canola seed, digestibility, lambs, ammonia-N, rumen $\mathrm{pH}$

\section{Introdução}

Canola (Brassica napus L.) é uma sigla canadense para "canadian oil low acid". É o nome registrado para uma variedade geneticamente modificada da colza, contendo menos que $2 \%$ do total de ácidos graxos, em ácido erúcico, e menos que $3 \mathrm{mg} / \mathrm{g}$ de $\mathrm{MS}$ em glicosinolatos (BAIER e ROMAN, 1992; MARQUES et al., 1992; BELL, 1993). É uma cultura de inverno que vem sendo utilizada para realização de rotação de culturas com o milho, introduzindo outra família, a crucífera, no lugar da também gramínea trigo, proporcionando melhor utilização, recuperação e conservação da fertilidade do solo (BAIER e ROMAN, 1992).

\footnotetext{
1 Parte da dissertação de mestrado do primeiro autor, na Universidade Estadual de Maringá - PR. Bolsista CAPES.

${ }^{2}$ Aluno de Pós-Graduação em Zootecnia - Doutorado - UNESP - Jaboticabal - SP.

${ }^{3}$ Professor do Departamento de Zootecnia - CCA - Universidade Estadual de Maringá, Av. Colombo, 5790 - $87020-900$ - Maringá-PR. Fone: (044) 263-4418.

${ }^{4}$ Centro Nacional de Pesquisa de Gado de Leite - EMBRAPA, Juiz de Fora-MG.

${ }^{5}$ Pesquisador da Agricultura and Agri-Food Canada - Lennoxville - P. Quebec - Canada.

${ }^{6}$ Bolsista de Aperfeiçoamento-CNPq.

${ }^{7}$ M. Sc. em Zootecnia. CESUMAR - Centro de Ensino Superior de Maringá.

${ }^{8}$ Aluno de graduação em Zootecnia - Universidade Estadual de Maringá.

*Pesquisador e Bolsista do CNPq. http/:www.uem.br - E-mail: gtsantos@uem.br
} 
A canola é considerada um alimento protéico, 23 a 25,5\% de proteína bruta na MS, porém de qualidade biológica inferior à da soja (ANDRADE, 1994), pois o valor nutritivo da proteína dietética para ruminantes depende da suplementação adequada de aminoácidos e amônia para a eficiente síntese microbiana (TITGEMEYER et al., 1989). Possui, ainda, altos teores de óleo (30 a 50\%) em suas sementes (HOLMES, 1980; BAIER e ROMAN, 1992), com altos níveis de ácidos graxos insaturados, como o oléico, linoléico e linolênico (SHAHIDI, 1990; ANDRADE, 1994).

Os ruminantes geralmente não toleram altos níveis de óleo na dieta (JOHNSON e McCLURE, 1972), devido à ação tóxica que exerce sobre as bactérias fibrolíticas, provocando diminuição da digestibilidade da fibra (ØRSKOV et al., 1978; PALLISTER e SMITHARD, 1987; e SWENSON e REENCE, 1993). Entretanto, SMITH et al. (1981) e RAFALOWSKI e PARK (1982) sugeriram que a inclusão de sementes integrais de oleaginosas não tem influência negativa sobre a degradação da fibra total do alimento.

A presença de ácidos graxos insaturados no rúmen provoca mudanças na proporção de ácidos graxos voláteis (SHAW et al., 1959; BROSTER et al., 1965; ROBERTSON et al., 1964). DEMEYER et al. (1967) mostraram que a adição de ácidos graxos insaturados, com 18 carbonos na cadeia, no fluido ruminal, aumentou a produção de propionato e lactato. Esta mudança pode ser atribuída à ação tóxica exercida pelos ácidos graxos insaturados sobre as bactérias metanogênicas pela utilização do hidrogênio livre, que seria utilizado na produção de metano, para produção de propionato (DEMEYER et al., 1967; VARMAN et al., 1968).

A peletização pode amenizar os efeitos nocivos da alta concentração de óleo nas dietas de ruminantes, pois protege as sementes da degradação ruminal, diminuindo a liberação do óleo no fluído ruminal. Outra contribuição importante do tratamento térmico seria a desnaturação de enzimas que funcionam como fatores anti-nutricionais, no caso da canola a mirosinase, responsável pela formação de precursores de glicosinolatos (FENWICK, 1982; SAHLU et al., 1984; e PALLISTER e SMITHARD, 1987). Os glicosinolatos quando hidrolizados pela enzima mirosinase ou $\mathrm{pH}$ neutro formam produtos que provocam a hipertrofia do fígado e da glândula tireóide, entre outros prejuízos à saúde animal (BELL, 1993).

Segundo HOOVER (1986), quando grande quantidade de concentrado é adicionado à dieta de rumi- nantes, ocorre aumento na taxa de passagem da digesta pelo rúmen, acarretando menor tempo de colonização e, por conseguinte, diminuição da degradação da fibra desse alimento (HOOVER, 1986). Outro fator importante, segundo DOYLE et al. (1988), é a rápida degradação da proteína dos alimentos, que libera amônia no meio ruminal e, com isso, aumenta a produção de proteína microbiana, que por sua vez, aumenta a produção de metabólitos da fermentação. Estes metabólitos fazem o $\mathrm{pH}$ ruminal cair mais rapidamente no tempo após a alimentação, diminuindo a digestão dos componentes da parede celular. Estes efeitos seriam observados mais evidentementes em pH abaixo de 5,8 (ØRSKOV e FRASER, 1975; SUTTON et al., 1983).

Este trabalho teve como objetivo avaliar a utilização do grão de canola, em diferentes formas de apresentação, na digestibilidade dos nutrientes da ração e no desempenho de cordeiros consumindo dietas com alta relação concentrado:volumoso.

\section{Material e Métodos}

Os tratamentos utilizados foram: feno de aveia + concentrado controle contendo farelo de soja (FS), feno de aveia + concentrado contendo canola em grão integral (CI), feno de aveia + concentrado contendo canola em grão quebrado (CQ) e feno de aveia + concentrado peletizado contendo canola em grão quebrado (CP). A inclusão da canola nos tratamentos CI e CQ ocorreu somente no momento do fornecimento aos animais. O feno de aveia foi triturado para ser fornecido aos animais. A ração total misturada foi fornecida na relação de $70 \%$ de concentrado e $30 \%$ de volumoso, com base na MS. As rações experimentais foram formuladas seguindo as recomendações nutricionais do NRC (1985). A canola utilizada neste experimento foi da variedade ICIOLA-41.

Para o ensaio de desempenho, 28 cordeiros machos inteiros, cruzados (fêmeas Corriedale e machos das raças Ile de France, Sufolk ou Bergamácia), com idade entre 60 e 90 dias, foram pesados e distribuídos ao acaso nos quatro tratamentos. Todas os tratamentos continham representantes de cada grupo genético disponível. Os cordeiros foram colocados em baias coletivas, sendo destinada uma baia com sete cordeiros para cada tratamento. Estes animais receberam alimentação ad libitum, incluindo minerais e vitaminas servidos em cochos comum a todos os animais, que foi fornecida duas vezes ao dia (às 9 e $16 \mathrm{~h}$ ), sendo as quantidades diárias acrescidas de $10 \%$, de 
810 Rev. bras. zootec.

forma a proporcionar sobras. Os animais tinham ainda livre acesso à água.

A formulação dos concentrados experimentais e a composição química das dietas experimentais encontram-se nas Tabelas 1 e 2, respectivamente.

Antes de entrarem no período experimental, os cordeiros receberam vermífugo e vitaminas ADE e permaneceram por um período de adaptação às condições ambientais de 30 dias. O período experimental foi de dezembro de 96 a março de 97 , perfazendo um total de 73 dias, quando os últimos animais atingiram peso vivo entre 31 e $33 \mathrm{~kg}$. As sobras de ração foram coletadas diariamente e seu peso anotado. Dez por cento das sobras totais diárias de cada tratamento foram identificados e armazenados em congelador. Ao final de cada semana, estas amostras foram agrupadas, formando uma amostra composta por tratamento, da qual se retirou uma subamostra de aproximadamente $10 \%$ do total, que foi utilizada para análise. Os animais foram pesados a cada 15 dias.

O ensaio de digestibilidade foi realizado segundo BRANCO et al. (1994). Foram utilizados dezesseis cordeiros machos inteiros, cruzados, com idade entre 180 e 210 dias. Os animais foram pesados e distribuídos ao acaso em gaiolas metabólicas individuais, com coletor de urina e piso ripado, sendo destinadas quatro gaiolas para cada tratamento. Os animais permanece-

\begin{tabular}{|c|c|c|}
\hline \multirow[t]{2}{*}{$\begin{array}{l}\text { Alimento } \\
\text { Feed }\end{array}$} & \multicolumn{2}{|c|}{$\begin{array}{l}\text { Concentrado } \\
\text { Concentrate } \\
(\mathrm{kg})\end{array}$} \\
\hline & $\begin{array}{c}\text { Sem canola } \\
\text { Without canola }\end{array}$ & $\begin{array}{l}\text { Com canola } \\
\text { With canola }\end{array}$ \\
\hline $\begin{array}{l}\text { Feno aveia } \\
\text { Oat hay }\end{array}$ & - & 10,838 \\
\hline $\begin{array}{l}\text { Milho quirera } \\
\text { Corn grain }\end{array}$ & 56,142 & 29,607 \\
\hline $\begin{array}{l}\text { F. trigo } \\
\text { Wheat meal }\end{array}$ & 15,000 & 6,644 \\
\hline $\begin{array}{l}\text { F. soja } \\
\text { Soybean meal }\end{array}$ & 24,178 & 21,796 \\
\hline $\begin{array}{l}\text { Canola grão } \\
\text { Canola grain }\end{array}$ & - & 28,571 \\
\hline $\begin{array}{l}\text { P bicálcico } \\
\text { Dicalcium P }\end{array}$ & 1,000 & - \\
\hline $\begin{array}{l}\text { Calcário } \\
\text { Limestone }\end{array}$ & 1,680 & 1,545 \\
\hline $\begin{array}{l}\text { Uréia } \\
\text { Urea }\end{array}$ & 1,000 & - \\
\hline $\begin{array}{l}\text { Sal comum } \\
\text { Salt }\end{array}$ & 1,000 & 1,000 \\
\hline
\end{tabular}

ram em um período de adaptação às condições ambientais de 15 dias. O período experimental foi de 7 dias. Foi feita coleta total de fezes, urina e sobras de ração. As fezes coletadas em sacolas, adaptadas aos animais, foram recolhidas diariamente e pesadas, sendo uma amostra de $10 \%$ do total diário armazenada em congelador. A urina total foi coletada diariamente em um balde contendo $20 \mathrm{~mL}$ de $\mathrm{HCl}(1: 1 \mathrm{~V} / \mathrm{V})$, medida volumetricamente, e uma amostra de $5 \%$ do volume total diário foi colocada em um recipiente com tampa rosqueável e armazenada em congelador.

A extração do líquido ruminal, para determinação do $\mathrm{pH}$, foi realizada após o ensaio de digestibilidade, com o auxílio de uma sonda esofágica. As coletas foram realizadas antes do fornecimento da alimentação aos animais, sendo considerado o tempo 0 , e nos tempos 2, 5 e 8 horas após o arraçoamento, seguindo recomendações de ORTOLANI (1981).

As amostras do alimento oferecido, das sobras e das fezes coletadas foram pré-secados em estufa de ar forçado a $55^{\circ} \mathrm{C}$ por 72 horas, sendo, posteriormente, moídas em moinho de martelo ou faca, conforme o tipo de material, com peneira de $1 \mathrm{~mm}$, para análises de MS, PB e EE, segundo SILVA (1990). As análises de FDA e FDN foram realizadas segundo GOERING e Van SOEST (1970), utilizando um digestor de fibras Fiber Analyser (ARKOM Co. - NY - USA). A energia bruta foi determinada em bomba calorimétrica adiabática (Calorimeter Parr).

As análises laboratoriais foram realizadas no Laboratório de Análise de Alimentos e Nutrição Animal e no Laboratório de Digestibilidade e Metabolismo Animal do Departamento de Zootecnia da Universidade Estadual de Maringá.

Os animais foram distribuídos em delineamento inteiramente casualizado. No ensaio de desempenho, foram utilizados sete animais por tratamento. No ensaio de digestibilidade, dezesseis animais foram usados, sendo quatro por tratamento. O efeito dos tratamentos sobre o desempenho dos cordeiros foi estudado por intermédio de análises de variância, e as médias foram comparadas pelo teste Tukey $(\mathrm{P}<0,05)$, com auxílio do sistema para análises estatísticas e genéticas (SAEG, 1993).

\section{Resultados e Discussão}

O consumo médio diário ( $\mathrm{g} / \mathrm{dia})$ de nutrientes pelos cordeiros consta da Tabela 3. As médias dos índices de desempenho alcançados pelos cordeiros, obtidas durante o período experimental, encontram- 
Tabela 2 - Composição química das dietas experimentais

Table 2 - Chemical composition of the experimental diets

\begin{tabular}{lcccccc}
\hline & \multicolumn{5}{c}{ Nutriente (\%) } \\
Nutrient \\
\cline { 2 - 7 } Tratamento & MS & PB & FDN & FDA & EE & EB(Mkcal/kg) \\
Treatment & $D M$ & $C P$ & NDF & ADF & EE & GE \\
\hline FS & 86,15 & 17,31 & 32,7 & 17,05 & 3,93 & 3517,07 \\
CI & 86,05 & 16,43 & 46,56 & 28,49 & 33,54 & 4748,19 \\
CQ & 86,48 & 16,93 & 41,91 & 26,52 & 16,60 & 4756,73 \\
CP & 87,00 & 15,94 & 37,49 & 21,51 & 18,03 & 4761,11 \\
\hline
\end{tabular}

${ }_{1}^{1}$ Analisado no Laboratório de Análise de Alimentos e Nutrição Animal - DZO/UEM.

${ }^{1}$ Analysed at the Food and Animal Nutrition Laboratory - DZO/UEM.

$\mathrm{FS}=$ feno de aveia + concentrado controle (Oat hay + control concentrate); $\mathrm{Cl}=$ feno de aveia + concentrado contendo canola em grão integral (Oat hay + whole canola grain concentrate); $\mathrm{CQ}$ = feno de aveia + concentrado contendo canola em grão quebrado (Oat hay + cracred canola grains concentrate); $\mathrm{CP}=$ feno de aveia + concentrado peletizado contendo canola (Oat hay + pelleted concentrate containing canola).

Tabela 3 - Consumo médio diário dos nutrientes das rações experimentais Table 3 - Average daily intake of the nutrients of the experimental diets

Nutriente $(\mathrm{g} / \mathrm{dia})^{1}$

Tratamento

Nutrient

Treatment

\begin{tabular}{lrrcc}
\cline { 2 - 5 } & FS & CI & CQ & CP \\
\hline MS $(D M)$ & 1097 & 1040 & 1064 & 1053 \\
PB $(C P)$ & 179 & 174 & 176 & 175 \\
FDA $(A D F)$ & 321 & 298 & 308 & 303 \\
FDN $(N D F)$ & 531 & 492 & 508 & 501 \\
EB $(G E)$, Mcal & 5 & 4 & 5 & 5 \\
Conversão alimentar $^{1}$ & 5,2 & 5,8 & 5,6 & 6,4
\end{tabular}

Feed:gain ratio

$\mathrm{FS}=$ feno de aveia + concentrado controle (Oat hay + control concentrate); $\mathrm{Cl}=$ feno de aveia + concentrado contendo canola em grão integral (Oat hay + whole canola grain concentrate); $C Q=$ feno de aveia + concentrado contendo canola em grão quebrado (Oat hay + cracred canola grains concentrate); $\mathrm{CP}=$ feno de aveia + concentrado peletizado contendo canola (Oat hay + pelleted concentrate containing canola).

1 Obtido pelo consumo total dos animais de cada baia coletiva dividido pelo número de cordeiros na baia (Obtained by the total intake of the animals of each collective stall divided by the number of lambs in the stall).

se na Tabela 4. As médias, por tratamento, obtidas durante o período experimental referentes a digestibilidade in vivo dos nutrientes estudados, encontram-se na Tabela 5.

As ingestões obtidas estão próximas à recomendada pelo NRC (1985), que é de 1,0 kg de MS/dia. Esperava-se que os animais alimentados com dietas contendo canola consumissem menos MS, devido à maior concentração energética das rações, o que não foi observado. Esta semelhança entre o consumo das dietas contendo ou não canola pode ser explicada pelo fato de serem compostas pela mesma relação concentrado:volumoso; com isso, a taxa de passagem seria semelhante, proporcionando ingestão semelhante. A alta relação concentrado:volumoso das dietas experimentais e a elevada concentração energética também podem influir na ingestão e digestão dos nutrientes, devido a receptores ruminais de ácidos graxos de cadeia curta, como os AGV's (Van SOEST, 1994). MIR (1988), trabalhando com níveis de inclusão $(0,3,4$ e $5 \%$ do total de alimento consumido) de ácidos graxos de canola na dieta de ovinos, não observou diferenças significativas na ingestão de MS (1,75; 1,69; 1,74; e 1,81 kg de MS/dia). O mesmo foi constatado por LOUGH et al. (1991), que, estudando a inclusão de semente de canola na dieta de cordeiros comparado com uma dieta contendo somente farelo de soja, observaram ingestões de 1345 e $1367 \mathrm{~g}$ de MS/dia, respectivamente. Ambos os autores observaram ingestões de MS superiorres a obtida neste trabalho, em virtude de os peso inicial (aproximadamente $23 \mathrm{~kg}$ ) e final (aproximadamente $50 \mathrm{~kg}$ ) dos animais utilizados por esses autores serem maiores.

Segundo BELL (1993), a canola é um alimento com elevada concentração de FDN e de FDA. BEAUCHEMIN et al. (1986), trabalhando com dietas contendo farelo de canola para cordeiros, observaram ingestão de FDN na ordem de $329 \mathrm{~g} /$ dia, valor inferior aos observados no presente experimento, $o$ que pode ser atribuído à forma de apresentação da 
812 Rev. bras. zootec.

Tabela 4 - Peso inicial e final e ganho médio diário (GMD) dos carneiros

Table 4 - Initial and final weights and average daily gain (ADG) of lambs

\begin{tabular}{lccccc}
$\begin{array}{l}\text { Desempenho } \\
\text { Performance }\end{array}$ & FS & CI & CQ & CP & CV $(\%)$ \\
\hline Peso inicial $(\mathrm{kg})$ & 17,2 & 17,1 & 18,0 & 17,3 & 18,0 \\
Initial weight & $(0,8137)$ & $(1,1813)$ & $(1,2345)$ & $(1,4158)$ & 32,0 \\
Peso final.(kg) & 33,1 & 31,3 & 32,7 & 13,4 & $(1,5398)$ \\
Final weight & $(1,7095)$ & $(0,9752)$ & $(2,1215)$ & 0,201 & 23,5 \\
GMD (kg/animal/d) & 0,219 & 0,194 & 0,202 & $(0,0256)$ & \\
ADG & $(0,0160)$ & $(0,0125)$ & $(0,01543)$ & \\
\hline
\end{tabular}

Valores entre parêntesis referem-se ao erro-padrão (Values in parenthesis refer to the standard error).

$\mathrm{FS}$ = feno de aveia + concentrado controle (Oat hay + control concentrate); $\mathrm{Cl}=$ feno de aveia + concentrado contendo canola em grão integral Oat hay + whole canola grain concentrate); $\mathrm{CQ}=$ feno de aveia + concentrado contendo canola em grão quebrado (Oat hay + cracred canola grains concentrate); $\mathrm{CP}=$ feno de aveia + concentrado peletizado contendo canola (Oat hay + pelleted concentrate containing canola).

Tabela 5 - Digestibilidade in vivo da matéria seca (MS), proteína bruta (PB), fibra em detergente neutro (FDN), fibra em detergente ácido (FDA) e energia bruta (EB) das rações experimentais e balanço de nitrogênio

Tabela 5 - In vivo digestibility of dry matter (DM), crude protein (CP), neutral detergent fiber (NDF), acid detergent fiber (ADF) and gross energy (GE) and nitrogen balance of the experimental diets

\begin{tabular}{|c|c|c|c|c|c|}
\hline \multirow{2}{*}{$\begin{array}{l}\text { Nutriente } \\
\text { Nutrient }\end{array}$} & \multicolumn{4}{|c|}{ Digestibilidade (\%) } & \multirow[b]{2}{*}{$\mathrm{CV}(\%)$} \\
\hline & FS & $\mathrm{CI}$ & $\mathrm{CQ}$ & $\mathrm{CP}$ & \\
\hline $\mathrm{MS}$ & 72,12 & 67,80 & 64,07 & 65,68 & 8,3 \\
\hline$D M$ & $(2,2728)$ & $(1,1489)$ & $(4,8364)$ & $(1,1851)$ & \\
\hline PB & 74,68 & 71,77 & 70,21 & 71,27 & 6,5 \\
\hline$C P$ & $(2,6921)$ & $(0,8989)$ & $(3,4488)$ & $(1,4808)$ & \\
\hline FDN & $46,84 \mathrm{ab}$ & $60,11 \mathrm{a}$ & $50,10 \mathrm{ab}$ & $38,88 \mathrm{~b}$ & 19,3 \\
\hline$N D F$ & $(5,0450)$ & $(0,7667)$ & $(6,7410)$ & $(3,5664)$ & \\
\hline FDA & $45,84 a$ & $54,19 a$ & $46,57 \mathrm{a}$ & $29,59 b$ & 18,7 \\
\hline$A D F$ & $(4,6416)$ & $(1,2862)$ & $(6,3741)$ & $(2,9566)$ & \\
\hline $\mathrm{EB}$ & 66,14 & 68,12 & 64,62 & 68,08 & 9,1 \\
\hline \multirow[t]{3}{*}{$C E$} & $(3,0621)$ & $(1,6317)$ & $(4,8171)$ & $(3,5177)$ & \\
\hline & \multicolumn{4}{|c|}{ Balanço de nitrogênio } & \\
\hline & \multicolumn{4}{|c|}{ Nitrogen balance } & \\
\hline $\mathrm{N}$-ingerido (g/dia) & $33,802 \mathrm{a}$ & $27,098 b$ & $30,058 \mathrm{ab}$ & $26,830 \mathrm{~b}$ & 5,4 \\
\hline$N$-intake (g/day) & $(1,2512)$ & $(1,7730)$ & $(0,6209)$ & $(0,0269)$ & \\
\hline $\mathrm{N}-\mathrm{fecal}(\mathrm{g} / \mathrm{dia})$ & 7,497 & 7,640 & 7,931 & 8,358 & 4,4 \\
\hline$N$-faecal (g/day) & $(0,1873)$ & $(0,0899)$ & $(0,4440)$ & $(0,0422)$ & \\
\hline N-urina & $19,755 \mathrm{a}$ & $14,433 b$ & $14,791 b$ & $15,429 b$ & 9,6 \\
\hline$N$-urine (g/day) & $(1,2907)$ & $(1,4896)$ & $(0,0637)$ & $(0,9451)$ & \\
\hline Retenção de N (g/dia) & $6,568 \mathrm{a}$ & $5,025 \mathrm{ab}$ & $7,336 a$ & $3,042 b$ & 19,1 \\
\hline$N$ retention (g/dia) & $(0,1478)$ & $(0,3732)$ & $(1,1287)$ & $(0,8763)$ & \\
\hline
\end{tabular}

Médias, na linha, seguidas de letras diferentes são diferentes pelo teste Tukey $(\mathrm{P}<0,05)($ Means, within a row, followed by different letters are different by Tukey test $[P<.05])$.

Valores entre parêntesis referem-se ao erro-padrão (Values in parenthesis refer to the standard error).

$\mathrm{FS}$ = feno de aveia + concentrado controle (Oat hay + control concentrate); $\mathrm{Cl}=$ feno de aveia + concentrado contendo canola em grão integral (Oat hay + whole canola grain concentrate); $\mathrm{CQ}=$ feno de aveia + concentrado contendo canola em grão quebrado (Oat hay + cracred canola grains concentrate); CP = feno de aveia + concentrado peletizado contendo canola (Oat hay + pelleted concentrate containing canola).

canola, visto que no presente trabalho foi utilizado grão integral de canola.

A ingestão de $\mathrm{PB}$ está de acordo com a recomendada pelo NRC (1985), que é de 167 e $191 \mathrm{~g} \mathrm{PB/dia}$ para cordeiros com 20 e $30 \mathrm{~kg} \mathrm{PV}$. Está também de acordo com BEAUCHEMIN et al. (1986), que, trabalhando com dietas contendo farelo de canola, observaram ingestão de $174 \mathrm{~g}$ de PB/dia. PETIT et al. (1997), trabalhando com grão de canola, observaram ingestão diária de $\mathrm{PB}$ de $175 \mathrm{~g} /$ dia para a forma extrusada e $183 \mathrm{~g} /$ dia para a forma não extrusada.

A eficiência alimentar obtida, levando em consideração o consumo médio e o média dos pesos dos animais para cada tratamento, foi similar à observada por MIR (1988), que encontrou valores de 5,5 e 5,6 kg de alimento/kg de ganho para os níveis estudados das fonte de gordura vegetal, sendo considerados bons resultados para cordeiros. BEAUCHEMIN et al. (1986), trabalhando com farelo de canola, obtiveram $3,67 \mathrm{~kg}$ de alimento $/ \mathrm{kg}$ de ganho. 
Os ganhos médios diários (GMD) foram semelhantes entre os tratamentos (Tabela 4). As dietas experimentais deste trabalho proporcionaram GMD menores que os observados por LOUGH et al. (1991), que, trabalhando com dieta contendo canola em grão, obtiveram GMD de 268 g. PETIT et al. (1997) também obtiveram GMD superiores aos deste trabalho, quando utilizaram canola em grão extrusada ( $249 \mathrm{~g} / \mathrm{dia})$ e canola em grão não-extrusada ( $245 \mathrm{~g} / \mathrm{dia})$. Como já mencionado, ambos os autores trabalharam com animais com peso inicial e final superiores aos do presente trabalho, proporcionando estes resultados mais elevados.

Não houve diferença significativa entre os tratamentos para digestibilidade da MS, PB e EB. Entretanto, foi observada diferença significativa para a digestibilidade da FDN e FDA (Tabela 5). As médias obtidas para digestibilidade da MS das rações foram inferiores às observadas por McALLISTER et al. (1992), de 82,0\%, e STANFORD et al. (1996), de $74,4 \%$, com dietas contendo farelo da canola. Por outro lado, foram superiores às obtidas por MIR (1988), que forneceu dietas com ácidos graxos acidulados de canola para carneiros castrados com valores próximos de $62 \%$, e similares aos obtidos por THOMAS et al. (1984), utilizando níveis crescentes de inclusão de farelo de canola proveniente de extração mecânica, e TAIT et al. (1986), que trabalharam com ovelhas alimentados com dietas contendo semente de canola refugadas pela indústria.

A inclusão do grão de canola na dieta de ruminantes não influenciou a digestibilidade da MS, PB e EB. Este resultado é corroborado por TAIT et al. (1986), que utilizaram para ovinos, como dietas experimentais, canola em grão refugado pela indústria, e por MIR (1988), que trabalhou com ácidos graxos acidulados de canola fornecidos para carneiros castrados.

Os dados obtidos para digestibilidade da FDN diferiram significativamente. Os resultados obtidos com os tratamentos FS, CQ e CP foram similares aos obtidos por DOYLE et al. (1988), quando comparada com a dieta com alto nível de concentrado (feno de aveia $+500-510$ g de concentrado). O conteúdo de óleo das dietas é um dos fatores que levam à diminuição da digestão da FDN, sendo evidenciado quando se comparam as dietas $\mathrm{CI}$ e CP. O teor de CP, por ter sofrido tratamento térmico, pode ter disponibilizado o óleo, liberando-o no ambiente ruminal, provocando, assim, diminuição da eficiência das bactérias fibrolíticas. Isto não foi observado na dieta CI, por conter grão inteiro, que dificulta a liberação do óleo.

Segundo ØRSKOV et al. (1978) e JOHNSON e McCLURE (1972), a inclusão de níveis superiores a $5 \%$ de gordura na dieta de ruminantes pode levar à diminuição da ingestão, associada à redução da digestão da celulose. No presente trabalho, a ordem decrescente das médias obtidas para digestão da FDN foi CI, CQ, FS e CP (Tabela 5). O tratamento CI provavelmente obteve a melhor média, devido à proteção da degradação ruminal proporcionada pelo tegumento da semente, que reduz o ataque dos microrganismos; com isso, o efeito negativo da gordura seria abrandado. Por outro lado, o tratamento CP, por ter sofrido tratamento térmico, pode ter disponibilizado o óleo, liberando-o no ambiente ruminal, provocando, assim, diminuição da eficiência das bactérias fibrolíticas (PETIT et al., 1997). O mesmo comportamento foi observado para a digestibilidade da FDA.

$\mathrm{A}$ ingestão de nitrogênio foi menor na dieta $\mathrm{CP}$, quando comparada à $\mathrm{FS}$, provavelmente por serem as dietas com menor e maior concentração de PB, respectivamente. O nitrogênio quantificado na urina dos animais mostra maior metabolização para a dieta FS, que não continha canola em sua formulação, e menor nas dietas que continham canola. Com isso, houve menor retenção de nitrogênio com a dieta $\mathrm{CP}$, que se deve ao tratamento térmico, o que resultou provavelmente em menor disponibilidade da proteína para o animal.

Houve redução do $\mathrm{pH}$ do fluido ruminal dos cordeiros alimentados com dietas contendo canola (Tabela 6). Observou-se diferença significativa para estes tratamentos no tempo 2 horas após o fornecimento da ração; todavia, no tratamento FS, foi constatada somente no tempo 5 horas após o arraçoamento. Entretanto, nenhum tratamento proporcionou $\mathrm{pH}$ inferior a 5,8, que, segundo $\varnothing \mathrm{RSKOV}$ et al. (1978), prejudicaria a degradação da FDN e FDA.

Ao contrário do que se esperava, não houve diferença significativa na concentração de propionato no líquido ruminal (Tabela 6), devido à presença de ácidos graxos polinsaturados no fluido ruminal. A inclusão de canola na dieta de ovinos proporcionou diminuição na produção de butirato e, ainda, menor concentração de N-amoniacal, evidenciando menor degradação da proteína da dieta experimental. 
814 Rev. bras. zootec.

Tabela 6 - pH ruminal nos diferentes tempos de coleta após alimentação e concentração de ácidos graxos voláteis Tabela 6 - Ruminal $\mathrm{pH}$ at different collection times and volatile fatty acid

\begin{tabular}{|c|c|c|c|c|c|}
\hline \multirow[t]{2}{*}{$\begin{array}{l}\text { Tempo de coleta }(\mathrm{h}) \\
\text { Collection time }\end{array}$} & \multicolumn{4}{|c|}{$\begin{array}{c}\text { Tratamento } \\
\text { Treatment }\end{array}$} & \multirow[b]{2}{*}{$\mathrm{CV}^{1}(\%)$} \\
\hline & FS & CI & CQ & $\mathrm{CP}$ & \\
\hline \multirow[t]{2}{*}{$\overline{0}$} & $7,07 \mathrm{bA}$ & 7,09abA & $7,23 \mathrm{abA}$ & $7,39 \mathrm{aA}$ & 2,63 \\
\hline & $(0,0851)$ & $(0,0566)$ & $(0,0925)$ & $(0,1241)$ & \\
\hline \multirow[t]{2}{*}{2} & $6,74 \mathrm{aAB}$ & $6,44 \mathrm{bB}$ & $6,70 \mathrm{aB}$ & $6,57 \mathrm{abB}$ & 2,14 \\
\hline & $(0,0380)$ & $(0,0635)$ & $(0,0473)$ & $(0,1130)$ & \\
\hline \multirow[t]{2}{*}{5} & $6,62 \mathrm{~B}$ & $6,52 \mathrm{~B}$ & $6,80 \mathrm{~B}$ & $6,80 \mathrm{~B}$ & 2,43 \\
\hline & $(0,1094)$ & $(0,0864)$ & $(0,0759)$ & $(0,0532)$ & \\
\hline \multirow[t]{2}{*}{8} & $6,86 \mathrm{AB}$ & $6,72 \mathrm{~B}$ & $6,77 \mathrm{~B}$ & $6,78 \mathrm{~B}$ & 4,10 \\
\hline & $(0,1736)$ & $(0,1483)$ & $(0,0849)$ & $(0,1500)$ & \\
\hline \multirow[t]{3}{*}{ CV $(\%)$} & 3,69 & 2,48 & 1,92 & 3,95 & \\
\hline & \multirow{2}{*}{\multicolumn{4}{|c|}{$\begin{array}{c}\mathrm{AGV}(\mathrm{mM} / \mathrm{ml}) \\
V F A\end{array}$}} & \\
\hline & & & & & \\
\hline Acético & $42,82 \mathrm{a}$ & $37,82 b$ & $34,89 b$ & $42,82 \mathrm{a}$ & 5,95 \\
\hline Acetic & $(1,2433)$ & $(0,0582)$ & $(0,5147)$ & $(1,0075)$ & \\
\hline Propionico & 15,66 & 16,93 & 12,94 & 16,23 & 4,58 \\
\hline Propionic & $(0,6245)$ & $(1,6271)$ & $(0,5457)$ & $(0,4324)$ & \\
\hline Butírico & $7,08 \mathrm{a}$ & $4,87 \mathrm{~b}$ & $4,08 \mathrm{c}$ & $4,29 b c$ & 4,64 \\
\hline Butiric & $(0,3227)$ & $(0,2033)$ & $(0,0629)$ & $(0,1525)$ & \\
\hline N-Amoniacal (mg/100 ml) & $12,17 \mathrm{a}$ & $8,69 \mathrm{ab}$ & $8,40 \mathrm{ab}$ & $7,66 b$ & 15,59 \\
\hline Ammonia $-\mathrm{N}(\mathrm{mg} / 100 \mathrm{ml})$ & $(1,8412)$ & $(0,9916)$ & $(0,5638)$ & $(0,4006)$ & \\
\hline
\end{tabular}

\section{Conclusões}

A utilização da canola, nas diferentes formas estudadas, não prejudicou a ingestão e a digestão de cordeiros, levando a desempenhos semelhantes entre os tratamentos utilizados.

\section{Agradecimentos}

À EMBRAPA/CNPGL, por ter realizado as análises de ácidos graxos voláteis e nitrogênio amonacal.

\section{Referências Bibliográficas}

ANDRADE, A. D. Ácidos graxos ômega-3 em peixes, óleos de peixes e óleos vegetais comestiveis. Maringá, PR : UEM, 1994, 67p. Dissertação (Mestrado em Química) - Universidade Estadual de Maringá, 1994.

BAIER, A.C., ROMAN, E.S. Informações sobre a cultura da "canola" no sul do Brasil. In: SEMINÁRIO ESTADUAL DE PESQUISA DE CANOLA, I, 1992, Cascavel. Anias... Cascavel: EMBRAPA/CNPT, 1992. p.1-9.

BEAUCHEMIN, K.A., McCLELLAND, L.A., JONES, S.D.M et al. 1986. Effects of crude protein content, protein degradability and energy concentration of the diet on growth and carcass characteristics of market lambs fed high concentrate diets. Can. J. Anim. Sci, 75:387-395.
BELL, J.M. 1993. Factors affecting the nutritional value of canola meal: A review. Can. J. Anim. Sci., 73:679-697.

BRANCO, A. F., ZEOULA, L. M., PRADO, I. N. et al. 1994. Valor nutritivo da polpa de citrus in natura para ruminantes. Unimar, 16:37-48 (Suppl. 1).

BROSTER, W.H., SUTTON, J.D., TUCK, V.J. et al. 1965. The effect of the addition of large amounts of cod-liver oil to the rations of yearling heifers on their rate of live-weight gain. $J$. Agric. Sci., 65:227.

DEMEYER, D.I., HENDERICKX, H.K. 1967. The effect of $C_{18}$ unsaturated fatty acids on methane production in vitro by mixed rumen bacteria. Biochim. Biophys. Acta., 134:484.

DOYLE, P.T., DOVE, H., FREER, M. et al. 1988. Effects of a concentrate supplement on the intake and digestion of a lowquality forage by lambs. J. Agric. Sci., 111:503-511.

FENWICK, G.R. 1982. The assessment of a new protein source - rapessed. Proc. Nutr. Soc., 41:277-288.

GOERING, H.K., Van SOEST, P.J. 1970. Forragefiber analyses. USDA Handbookn. 379. Washington, DC.: U.S. Departament of Agriculture. 20p.

HOLMES, M.R.J. 1980. Nutricion of the oil seed rape crop. London: Appl. Sci. Publ., p. 10.

HOOVER, W.H. 1986. Chemical factors involved in ruminal fiber digestion. J. Dairy Sci., 69:2755-2766.

JOHNSON, R.R., McCLURE, K.E. 1972. High fat rations for ruminnats. I. The addition of saturated and unsaturated fats to high concentrate rations. J. Anim. Sci., 34(3):501-509.

LOUGH, D.S., SOLOMON, M.B., RUMSEY, T.S. et al. 1991. Effects of dietary canola seed and soy lecithin in high-forrage diets on performance, serum lipids, and carcass characteristics of growing ram lambs. J. Anim. Sci., 69:3292-3298. 
MARQUES, U.M.L., COZZI, F.C.C.M.T., LAJOLO, M.F. 1992. Nutritional value of rapesseds (Brassica napus, L.) alone or in blends with corn or soybean. Cienc. Tecnol. Alim., 12:52-61.

McALLISTER, T.A., BEAUCHEMIN, K.A., McCLELLAND, L. A. et al. 1992. Effect of formaldehyde-treated barley or escape protein on nutrient digestibility, growth and carcass traits of feedlot lambs. Can. J. Anim. Sci., 72:309-316.

MIR, Z. 1988. A comparison of canola acidulated fatty acids and tallow as supplements to a ground alfalfa diet for sheep. Can. J. Anim. Sci., 68:761-767.

NATIONAL RESEARCH COUNCIL - NRC. 1985. Nutrient requirements of sheep. National Academy Press. 6. ed. Washington. 99p.

$\varnothing$ RSKOV, E.R., FRASER, C. 1975. The effects of procesing of barley-based supplements on rumen $\mathrm{pH}$, rate of digestion and voluntary intake of dried grass in sheep. Br. J. Nutr. Res., 34:493-500.

$\varnothing$ RSKOV, E.R., HINE, R.S., GRUNBB, D.A. 1978. The effect of urea on digestion and voluntary intake by sheep of diets supplemented with fat. Anim. Prod., 27:241-245.

ORTOLANI, E. L. 1981. Considerações técnicas sobre o uso da sonda esofágica na colheita do suco de rúmen de bovinos para mensuração do pH. Arq. Esc. Vet. UFMG, 33:269-275.

PALLISTER, S.M., SMITHARD, R.R. 1987. The digestion, by sheep, of diets containing different physical forms of rapeseed. J. Agric. Sci., 109:459-465.

PETIT, H.V., RIOUX, R., D'OLIVEIRA, P.S. et al. 1997. Performance of growing lambs fed silage with raw or extruded soybean or canola seeds. Can. J. Anim. Sci. 77:455-463.

RAFALOWSKI, W., PARK, C.S. 1982. Whole sunflower seed as a fat supplement for lactating cows. J. Dairy Sci., 65:1484-1492.

ROBERTSON, J.A., HAWKE, J.C. 1964. Studies on rumen metabolism. I. Effect of lipids on the concentration of ammonia, total and individual volatile fatty acids in the rumen. J. Sci. Food Agric., 15:274.

SAEG (Sistema para análises estatísticas e genéticas). 1993. Viçosa, MG: UFV/CPD, 1993.

SAHLU, T., SCHINGOETHE, D.J., CLARK, A.K. 1984. Lactational and chemical evaluation of soyabean meals heattreated by two methods. J. Dairy Sci., 67:1725-1738.

SHAHIDI, F. 1990. Canola and rapessed: production, chemistry, nutrition and processing technology. New York: Na Avi Book. p.165.

SHAW, J. C., ENSOR, W. L. 1959. Effect of feeding cod-liver oil and unsaturated fatty acids on rumen volatile fatty acids and milk fat content. J. Dairy Sci., 42:1238.

SILVA, D.J. 1990. Análise de alimentos (métodos químicos e biológicos). Viçosa, UFV, 2. ed., Imp. Univ. 165p.

SMITH, N.E., COLLAR, L.S., BATH, D.L. et al. 1981. Digestibility and effects of whole cottonseed fed to lactating cows. J. Dairy Sci., 64:2209-2215.

STANFORD, K., McALLISTER, T.A., LEES, B.M. et al. 1996. Comparison of sweet white lupin seed, canola meal and soybean meal as protein supplements for lambs. Can. J. Anim. Sci., 76:215-219.

SUTTON, J.D., KNIGHT, R., McAllAN, A.B. et al. 1983. Digestion and synthesis in the rumen of sheep given diets supplemented with free or protected oils. Br. J. Nut. Res., 49:419-432.

SWENSON, M.J., REENCE, W.O. 1993. Dukes, fisiologia dos animais domésticos. Ed. Guanabara Koogan, Rio de Janeiro.

TAIT, R.M., BEAMES, R.M., LITSKY, J. 1986. Grain screenings as a dietary component for pigs and sheep. II Animal utilization. Can. J. Anim. Sci., 66:483-494.

THOMAS, Verl M., KATZ, R.J., AULD, D.L. et al. 1984. Value of mechanically extracted rape and safflower oilseed meals as protein supplements for growing lambs. Anim. Feed Sci. Technol., 11:269-277.

TITGEMEYER, E.C., MERCHEN, N.R., BERGER, L.L. 1989. Evaluation of soybean meal, corn glutem meal, blood meal and fish meal as sources of nitrogen and amino acids disappearing from the small intestine of steers. J. Anim. Sci., 67:262-275.

Van SOEST, D.J. 1994. Nutritional ecology of the ruminant. Cornel University Press, Ithaca, 2.ed. 476p.

VARMAN, P.N., SHULTZ, L.H., NICHOLS, R.E. 1968. Effect of unsaturated oils on rumen fermentation, blood components, and milk composition. J. Dairy Sci., 51(12):1956-1963.
Recebido em: 23/07/98

Aceito em: 25/01/99 